\title{
Reagan's new space policy contains little science
}

\section{- Hopes for a commerical launcher - Military matters remain a priority}

\section{Washington}

THE White House last week released details of a new comprehensive space policy signed by President Ronald Reagan at the start of January.

As previously reported, a large part of the policy is aimed at encouraging a commercial space sector to complement the civil and defence space sectors (see Nature 331, 380; 1988). It also establishes the long-range goal of expanding human presence beyond Earth orbit, first to a lunar base and ultimately to Mars.

Towards that end, a new technology and development programme, dubbed Project Pathfinder, is due to be started in the 1989 fiscal year beginning next October.

Although the new policy explicitly endorses the construction of a permanently manned space station, it also calls on the National Aeronautics and Space Administration (NASA) to solicit proposals for a different orbiting space facility "suitable for research and commercial manufacturing" to be built, operated and paid for by the private sector. NASA administrator James Fletcher says NASA will seek proposals at once, and expects a contract to be signed by July of this year. Only one company, Space Industries Inc., of Houston, Texas, is known to be ready with a proposal.

Although this Industrial Space Facility (ISF) is intended as a private venture, it will nevertheless depend heavily on government money. Fletcher says the government plans to lease 70 per cent of it once it is in service. Space Industries reckons this income, worth approximately $\$ 700$ million over five years, is necessary to make the project a financial reality.

In addition to ISF, the Reagan administration will also support development of "Spacehab", a commercially owned and operated shuttle module that would also permit human operations in space.

The new policy will take the US government permanently out of the commercial launch business, unless a commercial payload has a specific need for the lift capabilities of the space shuttle. This reiterates a policy first articulated in 1984 putting the Department of Transportation in charge of encouraging a commercial launch industry. Private industry is also being encouraged to take advantage of space aboard the space station once it is launched.

The new policy also makes it quite clear that space activities are needed to "strengthen the security of the United States". Although the United States remains committed to exploration of space for "peaceful purposes", it nonetheless insists that this allows the pursuit of national security goals.

NASA will retain responsibility for space science. But with the financial burdens of building a new shuttle to replace the Challenger, constructing the space station, developing a new heavy lift vehicle, and supporting the new ISF, even the healthy budget increases expected in the 1989 budget will leave precious little for new scientific activities. Joseph Palca

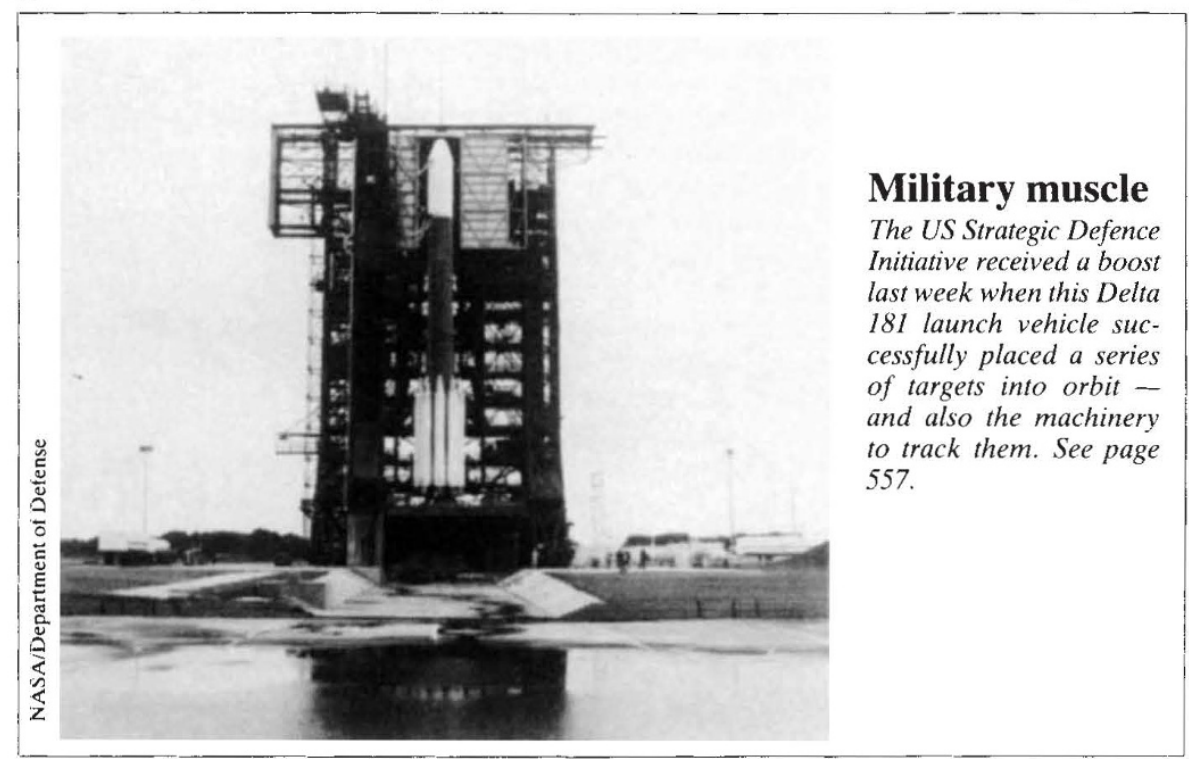

ESA and NASA get it together

Paris

Two areas of uncertainty left over from last November's ministerial meeting of the European Space Agency (ESA), in The Hague, regarding Europe's long-term space plan and programmes seem now to have been settled (see Nature 330, 302. 1987). The news, like the curate's egg, is good in parts.

The good news is that a compromise has finally been reached with the US National Aeronautics and Space Administration (NASA) regarding joint plans for the $\$ 20,000$ million international space station (see Nature 331, 469; 1988). ESA, which wants to contribute a 'package' of orbiting laboratories - called Columbus - to interface with a manned US space platform, could not accept that, as major sponsor, the United States should have responsibility for administration of the entire project.

After a week of negotiations in Washington in early February, ESA delegates returned with outlines for a compromise. While the United States will have the final say in decisions relating to the space platform, other countries will retain authority over the elements they contribute. This means that ESA member states will be able to veto use of the Attached Pressurised Module and ManTended Free-Flying Laboratory for military experiments. But the United States will still be able to carry out experiments of a military nature within the main space station, so long as these do not involve actual testing of weapons. The ESA charter says its activities must be of a peaceful nature only.

Other bones of contention carried over from The Hague concerned arbitration procedures in the event of a dispute between partners, and patent rights to discoveries arising from microgravity experiments. Although lawyers will now have the difficult task of phrasing the exact terms of a final agreement, US jurisdiction will apply only to the space station.

The bad news, at least for Britain's space industry, is that $\mathrm{Mr}$ Kenneth Clarke, Minister of State for Trade and Industry, has confirmed that Britain will not take part in either the Columbus programme or the building of the Ariane 5 heavy-lift rocket launcher.

ESA officials in Paris were reluctant to comment on Britain's non-participation, but hopes were never high that Clarke would change his mind. Member governments now have just over a month to consider the text drawn up in Washington, in time for the next ESA Council meeting on 17 and 18 March.
Peter Coles 